\title{
Biofuels Are Not the Full Answer, but They Can Be Part of a Solar-Oriented Solution to Our Energy-Climate Dual Crisis
}

\author{
Nawwaf Kharma ${ }^{1}$, Lance Lafontaine ${ }^{2}$ and Richard Fenster ${ }^{3}$ \\ ${ }^{1,3}$ Electrical \& Computer Engineering Dept., Concordia University, Montreal (QC), Canada \\ ${ }^{2}$ Biology Dept., Concordia University, Montreal, Quebec, Canada
}

Correspondence should be addressed to: Nawwaf Kharma; kharma@ece.concordia.ca

Received date: 21 June 2014; Accepted date: 22 October 2014; published date: 26 August 2016

Academic Editor: M. Abul Kalam

Copyright (C) 2016. Nawwaf Kharma, Lance Lafontaine and Richard Fenster . Distributed under Creative Commons CC-BY 4.0

\begin{abstract}
Biofuels are part of a trend towards increased utilization of local resources for energy generation, especially those with greenhouse gases' reduction benefits. In this paper, we argue that photosynthesis dependent biofuels - with a practical maximum of $2 \%$ energy conversion efficiency - can only satisfy a fraction of the world's liquid fuel needs. Even that cannot be achieved without the deployment of 2 nd generation biofuel production processes - still under development - which accept cellulosic and microalgal feed stocks, not food crops. For these feed stocks to be sustainably cultivated, they must be grown on non-arable lands using limited amounts of irrigation water and fossil-fuel based agrichemicals. Additionally, biofuels pose their own unique set of issues to consider such arable land use, water consumption among other metrics. Finally, biofuels should be viewed as just one way of converting sunlight into energy besides other means such as solar heating and photovoltaics, with the latter option realizing an energy conversion efficiency exceeding $10 \%$. By reviewing the potential alternatives to oil and petrol based fuels, it can be seen that biofuels are only a viable replacement when used in conjunction with other renewable energy sources.
\end{abstract}

Keywords: Consumption, policy, alternatives, dual-energy

Cite this Article as: Nawwaf Kharma, Lance Lafontaine and Richard Fenster (2016)," Biofuels Are Not the Full Answer, but They Can Be Part of a Solar-Oriented Solution to Our Energy-Climate Dual Crisis" International Journal of Renewable Energy and Biofuels, Vol. 2016 (2016), Article ID 650634, DOI: 10.5171/2016.650634 


\section{Introduction}

The world is going through two parallel global crises: one commonly called 'Peak Oil' and another probably caused by the burning of oil and other fossil fuels, 'Climate Change.' Climate change is an important topic worthy of a separate paper, while the focus of this one is on peak oil or rather, the economic and ecological feasibility of the substitution of all or part of fossil oil with biologically sourced or synthesized oil.

There is no argument about the finiteness of the remaining discovered and undiscovered fossil oil and its precursors. In fact, there is general agreement that the demand for oil, globally, will outstrip conventional and unconventional supply (excluding coal) in 2020-2035 (Luciani, 2003; Sorrell et al., 2010b; Greene et al., 2006; IEA, 2008). This does not mean that the world fossil oil reserves will be exploited by 2035. It does mean, however, that the price of oil and oil products will be on an upward trajectory, signaling an end to the era of cheap oil-based energy. This may not only inflate heating costs in colder regions (e.g., North America) but also, indirectly, a long list of basic goods and services, such as food and transportation, globally.

This paper is motivated by a central argument that photosynthesis dependent biofuels can only satisfy a fraction of the world's liquid fuel needs. Hence, biofuels should be viewed as one of the many ways of converting light into energy, besides many other proven means such as solar heating and photovoltaics, which have already achieved greater efficiencies than photosynthesis.

\section{The future of fossil fuel supply}

Although it is difficult to predict the ultimately recoverable resources (URR) of a particular area due to highly variable economic, technical, mathematical and geological factors (Sorrell et al., 2010b; Sorrell et al., 2010a), a global estimate from the 2000 USGS World Petroleum Assessment is about 3.35 trillion barrels of conventional oil (or TBO) (USGS, 2000). In 2002, the US Geological Survey published a comprehensive survey of 128 territories containing $95 \%$ of the world's discovered and potential oil and gas reserves (Armaroli and Balzani, 2007). It concluded that the remaining discovered and undiscovered reserves of oil from conventional and unconventional sources (e.g., tar sands) are 2.3 trillion barrels of oil equivalent (or TBOE). The inclusion of natural gas in the sum takes the total of 4.88 TBOE. In 2008, a separate study conducted by the International Energy Agency (or IEA) estimated an ultimately recoverable resource value of 3.5 trillion barrels of conventional oil left (IEA, 2008). Unless new fields are discovered on the Moon, this is a fixed limit, which includes hard-to-access, off-shore and arctic fields (Sorrell et al., 2010b; Armaroli and Balzani, 2007), making up $75 \%$ of the undiscovered portion of the global fossil oil and gas reserves (Armaroli and Balzani, 2007).

The IEA reported a daily global consumption of liquid fuels of 85.41 megabarrels (Owen et al., 2010) for 2008. In the best possible scenario, at this rate of consumption, equivalent to 31.2 gigabarrels a year or $0.0312 \mathrm{TBO} /$ year and assuming zero growth in world demand entails a complete depletion of oil and gas reserves in just over 100 years. This quantity of time can be perceived to be a bit longer than one average human life-time in a developed country. In fact, the earth's population is growing in size, and poorer countries are striving for higher levels of material and energy consumption. This has resulted in an average of $2 \%$ yearly growth in global energy demand (Armaroli and Balzani, 2007). The developed countries involved in the Organisation for Economic 
Cooperation and Development (OECD), who currently consume more than half of the world's oil annually, have a predicted $12 \%$ increase in oil consumption throughout the 25-year span between 2010 and 2035, while non-OECD countries are predicted to have a $72 \%$ increase. As is rather evident, fuel consumption has also been correlated significantly with economic development (IPAA, 2013).

Considering this limited time span and expanding rate of demand, 'Peak Oil' is a near-term crisis that must be responded to as expediently as possible, if we are to stabilize energy costs and stabilize energy supplies beyond our children's life-time. In truth, the switch from conventional to unconventional oil given the upcoming resource limit will likely not be quick enough to prevent a global oil shortage and the associated economic effects considering constraints like cost of production, energy yield and the recent rate of advancement in production technologies (Bentley, 2002).

The earth may be viewed as a large space ship hurtling in space towards no particular end and receiving no help in that endeavour, except for its two solar endowments: a cooling but very hot core largely covered by liquid water and solar radiation which bathes it and is very partially converted into energy by humans, plants and other entities. One of those forms is biofuels synthesized by human engineered processes.

\section{First generation biofuels}

Commercially available biofuels come in two flavours: bioethanol and biodiesel. Bioethanol is made through a process dominated by yeast or bacterial fermentation from 6- and 5-carbon sugars. The sugars themselves are made by plants via photosynthesis and are then harvested and processed into a form that allows for fermentation, leading to distillation and distribution (Bothast and Schlicher, 2005). Biodiesel is made from natural triglycerides in vegetable oils, such as palm and soy oil, but also animal fat, via a process of transesterification (Srivastava and Prasad, 2000). This is an alkali-catalyzed reaction, where the glycerol of the triglycerides is replaced with an alcohol: ethanol or methanol (Srivastava and Prasad, 2000). The result must still be refined to remove glycerol and other by-products before the remainder can be used as fuel (Srivastava and Prasad, 2000).

In order for a biofuel to be desirable, it is important that it exhibits the following characteristics, on the basis of total life-cycle analysis. The biofuel manufacturing process (and byproducts) should provide consumers with more energy than is required for the fuel's generation. This is called positive net energy balance (or NEB). However, a small positive energy balance will, in most cases, not justify the production of that fuel, as there are other characteristics to consider. This is because every successful biofuel is going to have to be economically feasible at some scale of production relative to competing fuels, whether from fossil or renewable sources (Hill et al., 2006).

The true economic feasibility of the generation of a biofuel is also important (Yeboah et al., 2012), and it is not equivalent to a positive NEB, unless - we propose - all internal and external costs and benefits of the process of generating and consuming the biofuel (and its byproducts) are converted into energy equivalents (Farrell et al., 2006). The hardest part of doing that is quantifying the so-called 'externalities', which reflect costs and benefits that do not impact the profitability of the biofuel maker, but are incurred by others. Real economic feasibility would have to take into consideration capital and decommissioning costs as well as direct and indirect government subsidies in the form of quotas, regulations and health care benefits. A feasibility study as just described could be called a total unsubsidized economic feasibility (or UEF). 
Another consideration of biofuel production is, what we call, total environmental impact (or TEI), which is the sum of all environmental impacts - not just on humans, but the global ecosystem (Scharlemann and Laurance, 2008). There is a lot of work in this area (Hertwich et al., 1997) but no agreed international measure yet. Touted positive impacts of biofuels include the lower net emissions of $\mathrm{CO} 2$ compared to those generated by an energy-equivalent amount of fossil fuel (Scharlemann and Laurance, 2008; FAO, 2008). Even this measure is misleading, as what really matters for long-term sustainability of biofuel production is the net accumulated amounts of all pollutants, including all greenhouse gases, lost $\mathrm{CO} 2$ sinks, polluting agricultural inputs, depleted soil and water resources as well as lost diversity (Gasparatos et al., 2013; Fargione et al., 2010; FAO, 2008), which must be taken into account, on a perpetual basis.

It is usually the case that a high level of profitability (accompanied by low risk to capital) would trump all other factors, but since a high NEB is why many biofuel advocates are engaged in the whole exercise, a high NEB is usually an important characteristic of any biofuel (Hill et al., 2006). Finally, since a high environmental impact would not just kill the proverbial fish in Mexico (and some of our own descendants, soon enough), but also risk a company's own profitability (Knight and Pretty, 1996) (as illustrated by recent oil spill disasters), many companies do try to improve the reality and image of the impact of their economic activity on the natural environment (Rothenberg et al., 2002; Robbins, 2001; Hill et al., 2006; Carlson et al., 1993).

In the following sections, we will assess the feasibility of particular biofuels, guided mainly by the three factors discussed above or their best available equivalents.

\section{Ethanol from food crops}

The NEB for corn (which is the main source of bioethanol in the United States) is low, hovering around 25\% (Hill et al., 2006). In fact, taking away the energy attributed to one byproduct of the process (Dried Distillers Grains with Solubles, used in animal feed) would eliminate all of that net positive balance (Hill et al., 2006) and render the technology useless.

The positive environmental effects of bioethanol production appear to be limited to the reduction of certain air pollutants. These include reduced emissions for $\mathrm{CO} 2$ (Farrell et al., 2006; Balat et al., 2008), CO, volatile organic compounds (VOC) and certain particulate matter (PM10, less than 10-6 $\mathrm{m}$ in diameter) (Hill et al., 2006; He et al., 2003). However, when taking sulfur and nitrogen oxides into account, total life-cycle emissions are higher with the E85 blend ( $85 \%$ gasoline to $15 \%$ bioethanol) than emissions from pure gasoline, on an equal amount of energy-released-upon-combustion basis (Hill et al., 2006). In addition, corn production (whether for bioethanol or not) has net negative impacts due to the bleaching of agricultural inputs, especially nitrogen, phosphorus, pesticides and herbicides from the land and into various bodies of water above and below ground (Kim and Dale, 2005), deemed eutrophication, and the type of processes and procedures used in modern bioethanol production will vary its environmental impact significantly. Oddly enough, N20, which is microbially produced from plant biomass when tilled into nitrogenfertilized soil, is a much worse greenhouse gas than CO2 (Hill et al., 2006; Robertson et al., 2000; Ravishankara et al., 2009; EPA, 2013).

In terms of economic profitability, or specifically, UEF: that depends on the difference between the price of bioethanol's main competitor, gasoline, and the unsubsidized cost of production of bioethanol from corn. Even diminishing

Nawwaf Kharma, Lance Lafontaine and Richard Fenster (2016), International Journal of Renewable Energy and Biofuels, DOI: 10.5171/2016.650634 
subsidies, at current US gasoline prices hovering around 80 cents per litre (Bloomberg, 2013), corn-based bioethanol production in the US is competitive with gasoline on the international markets (Goldemberg, 2007).

If bioethanol production from a sugaryielding crop is to be expanded then it ought to be done using sugarcane. Sugarcane has a total cost of production of 195.9 US dollars $/ \mathrm{m} 3$, much lower than that of corn (336.1 US dollars/m3, which includes government subsidies of 107.3 US dollars/m3) (Goldemberg, 2008). Its net energy balance - expressed as a fraction - is between 8.2 and 10, much greater than that of corn, which is $\sim 1.3$ (Goldemberg et al., 2008; Goldemberg, 2008). In fact, bioethanol producers in Brazil are net energy contributors to the national electric grid, since most of the energy they consume comes from bagasse burning. In addition, bioethanol from sugarcane produces 91\% less $\mathrm{CO} 2$ than gasoline, compared to bioethanol made from corn (18\%) (Goldemberg et al., 2008; Goldemberg, 2008).

While expanding corn-based bioethanol production in the US is limited in scope (more on this issue below), it is most likely that any significant production of bioethanol will come from sugarcane, and the best environment for growing sugarcane is the tropics, especially Brazil. A common concern is that such an expansion would threaten the Amazonia region, but it turns out that sugarcane production is done on pastureland in south-eastern states (including Sao Paulo) (Goldemberg and Guardabassi, 2009). In 2005 , the density of utilization of that pastureland in the state of Sao Paulo was 141 heads of cattle $/ \mathrm{km} 2$ and is $\sim 100$ in Brazil as a whole (Goldemberg and Guardabassi, 2009). There are 200 thousand square kilometers of pastures in Brazil, so utilizing that area as cattle pasture at a $10 \%$ additional efficiency would release 200000 $\mathrm{km} 2$ of land to potential sugarcane production, compared to the actually utilized area in 2009 of $62000 \mathrm{~km} 2$. This area is sufficient to cover $10 \%$ of the world's gasoline demand (Escobar et al., 2009).

Nevertheless, using so much land for fuel instead of food production is a hugely contentious issue, especially if there are still masses of hungry humans around the world. Also, one should never neglect the massive environmental effects of massive monocultures (Goldemberg et al., 2008; Gasparatos et al., 2013; Fargione et al., 2010), including pollution and biodiversity loss. (Goldemberg et al., 2008; Gasparatos et al., 2013; Fargione et al., 2010), Land in Brazil's south eastern plains is some of the most biodiverse in the world (Giulietti et al., 2005).

In any case, if bioethanol production is to expand, then it is important to optimize its production by (1) improving the renewable source's photosynthetic yield; (2) using crops that yield the maximum amount of convertible biomass per acre; (3) enhancing the efficiency of the fermentation process via metabolic engineering; (4) and improving the efficiency of internal combustion engines. Bioethanol production can expand in Brazil, but can it expand, worldwide, to cover world needs?

\section{Maximal supply of bioethanol}

In 2009 , the amount of bioethanol used as fuel accounted for about $0.7 \%$ of global oil production and $2 \%$ of gasoline consumption. All this originally comes from plants that cover about $1 \%$ of the world's arable land (Goldemberg and Guardabassi, 2009).

Ethanol produced by the United States is made predominantly from corn (Dunn et al., 2013). Corn is a food crop, even when not directly consumed by people, because it is an important source of starch (Rooney and Pflugfelder, 1986) used in making tens of processed food ingredients (e.g., corn syrup, malt and thickeners). Corn is also the mainstay of animal feed products, with $60 \%$ of all the corn produced in the United States being used for livestock feed (Olson, 2006). 
The fact that corn is a food crop naturally led to fears that the utilization of corn for bioethanol will reduce food supply and/or increase food prices.

The prices of crops used for bioethanol (and biodiesel) production have in fact been on an upward trend since 2000 (Goldemberg and Guardabassi, 2009). Although many factors affect the price of food crops, such as increased world population and higher energy prices, biofuels have been estimated to be an important and causative factor (Mitchell, 2008). In addition, the biggest and most successful producer of bioethanol in the world, Brazil, has not suffered an increase in sugar prices due to its massive sugarcanebased bioethanol energy policy, consuming about $50 \%$ of their sugarcane output (Goldemberg and Guardabassi, 2009). However, quantity has a quality of its own, and as such, it is necessary to investigate how much land is necessary to grow sugar crops to make ethanol. If the area is great then engaging in massive biofuel crops production will, without doubt, put upwards pressure on food prices and availability, as can already be seen with corn in the United States (Mitchell, 2008).

Proceeding from fundamentals, we view photosynthetic organisms (mainly plants) as light to chemical energy converters. The practically unattainable theoretical maximum for the efficiency of conversion of light to chemical energy (stored as biomass) via photosynthesis is $11.9 \%$ (Walker, 2009). However, taking environmental factors into consideration, such as light and temperature, leads us to a maximum practical efficiency of $4.5 \%$ for C3 plants and microalgae and 6\% for C4 plants (Walker, 2009). The actual current photosynthetic conversion rate is about $1 \%$, and may after decades of research be increased to $2 \%$. When translating a photosynthetic efficiency of $4.5 \%$ into grams of biomass per square metre of a given plant growing environment (say, the United States) gives us a maximum of 54.4 grams of biomass per 12-hour day. A more reasonable estimate for maximum biomass per square metre is 14 grams/m2/day (Walker, 2009), which is closer to the 11.8 grams $/ \mathrm{m} 2 /$ day resulting from a theoretical computation assuming a $1 \%$ photosynthetic efficiency.

Continuing along the same lines allows us to compute an estimate for the quantity of land required to meet the requirements for all cars registered for highway use in the United States during 2005. If we assume that corn crop yields allow for $100 \%$ conversion to fuel, one acre of corn will provide sufficient fuel for a travel distance of 8000 miles or $12875 \mathrm{~km}$ per year (Walker, 2009). Using the EPA average of 12000 miles traveled annually for a passenger car (EPA, 2008) and some simple math, we can deduce that 1.5 acres are needed to meet the demands for a personal vehicle. In 2009, the United States Department of Transport had recorded a value of 193979654 light duty vehicles registered for highway use (RITA, 2013). Using the assumption of one acre is needed per vehicle, this implies 290969481 acres or $1.178^{*} 106 \mathrm{~km} 2$ of land is needed to meet fuel requirements. The total land in the United States is $9826675 \mathrm{~km} 2$ and that $16.29 \%$ of this value is currently arable (CIA, 2014). This yields approximately $1.601 * 106 \mathrm{~km} 2$ of total available arable land in the United States. By using these values and dividing the required land for fuel production over the available arable land, we can then see that to meet the average fuel requirements of the United States for highway vehicles in 2009, would require approximately $73.63 \%$ of the available arable land available in the country. Figure 1 demonstrates the growth in land required to meet demands by using 1.5 acres of crops per vehicle to meet the fuel demand imposed by increased amounts of light duty vehicles registered for highway use. 


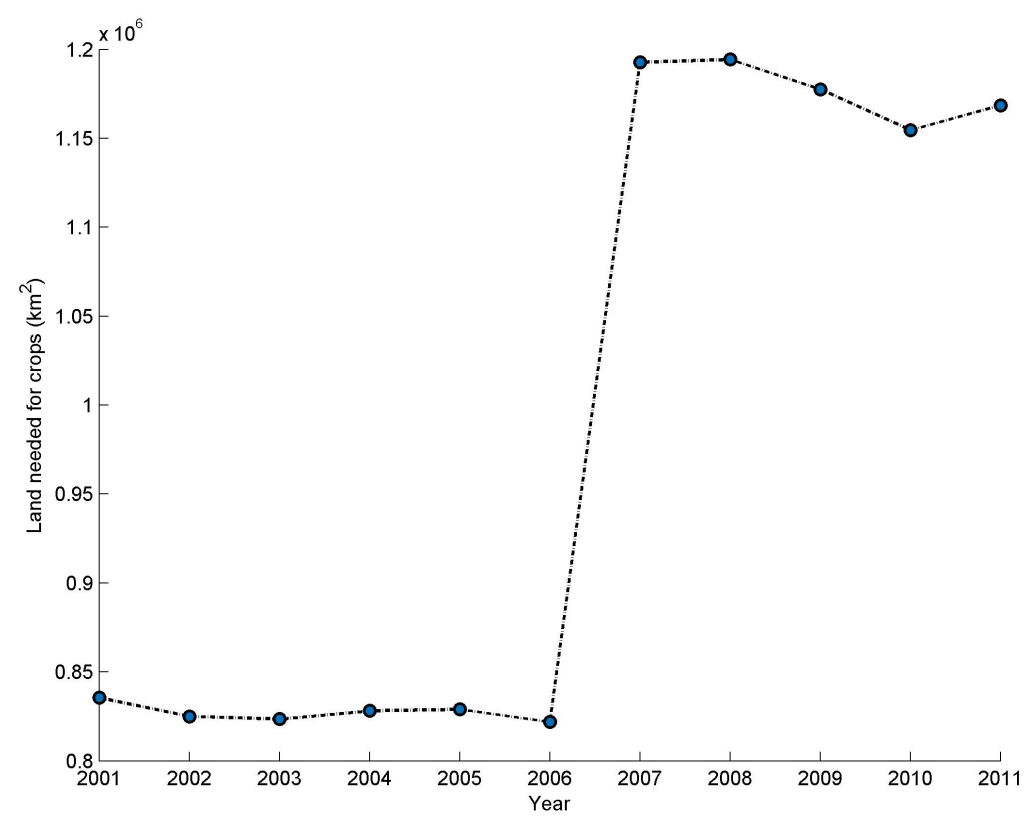

Figure 1: Land requirements to meet fuel demand of light duty vehicles registered in the United States

Hence, even while considering the best possible scenarios and the advancements in technology for efficient biofuel conversion, it is impossible for bioethanol to replace gasoline as the main transportation fuel in the United States - similarly, the world - and any major ramping-up of biofuel production will only serve us unfavourably by impacting food prices due to the sheer size of arable land.

\section{Diesel from food crops}

Next to gasoline, diesel is the most widely used transportation fuel, especially for heavy-duty and industrial machinery. Due to the great variability in the models and contributing factors to NEB, calculated values for the energy ratio of biodiesel were found to be generally inconsistent, but a recent comprehensive study presents an energy ratio of 2.55 for biodiesel made from soy
(Pradhan et al., 2008), while another source provides the ratio of 2.42 for palm oil-based biodiesel (Pleanjai and Gheewala, 2009). In Brazil, the yield of biodiesel made from palm oil is reported to be a whopping 273000 litres/km2 (compared to 88000 litres $/ \mathrm{km} 2$ for soy, its US-based biodiesel competitor) (Escobar et al., 2009). In addition, comparing the former to soy oil, sunflower oil, canola oil and cottonseed oil, palm oil along with tallow have the highest percentage of saturated and mono-saturated fats, which result in biodiesels with the best fuel properties such as stability and cetane number, although they would also have the highest melting points, rendering them problematic for colder climates, such as Canada's (Nogueira, 2011).

In terms of economic feasibility, the cost to produce palm oil-based biodiesel is $\sim 45$ cents per litre, which is about as much as soy-based biodiesel. This cost is higher than 
that of tallow-based biodiesel (Escobar et al., 2009) and is near-competitive with fossil diesel. However, despite Brazilian government incentives, quotas and regulations encouraging biodiesel production (some specifically targeting palm oil), biodiesel production grew but the main feedstock for biodiesel production remained soy (at $80 \%$ ), followed by tallow (Nogueira, 2011).

From an environmental perspective, the amount of $\mathrm{CO} 2$ in grams generated through the production of a $\mathrm{kg}$ of palm oil is reported to be $868 \mathrm{~g} / \mathrm{kg}$, relative to $2970 \mathrm{~g} / \mathrm{kg}$ for fossil diesel. This value is a supposed reduction of $71 \%$ in $\mathrm{CO} 2$ emissions (Nogueira, 2011). However, this does not come without the usual use of fertilizers such as nitrogen and phosphorus as well as herbicides and pesticides involved in the production process. These not only contribute to the energy demands and $\mathrm{CO} 2$ releases of the biodiesel production process, but they also pollute the environment. Nonetheless, Yusoff, (2006) reports that palm oil is the most efficient in that it requires the least amount of herbicide, pesticide, fertilizer and energy input for oil yield in comparison to three other major crop competitors, being soy, sunflower and rapeseed.

Relatedly, the NEB for biodiesel from palm oil is good but not as good as that of bioethanol from sugarcane. The Brazilian Foundation for Sustainable Development (FBDS) reports an energy output/input ratio of 5.6 for palm-oil biodiesel. The economic feasibility of the production of biodiesel from palm oil is possible but still to be proven, despite the Brazilian government's efforts to encourage it (Ortiz et al., 2006). These varied net energy balances are plotted in Figure 2. It is rather visible that sugarcane has a substantially better net energy balance than corn, soy and palm oil. Environmentally, there is an ongoing tension between short-term economic feasibility (following a profitmaximizing model of production) and longterm human and ecosystem health. As for supply, it is unlikely that a great expansion of supply will be politically feasible, for as long as it is done on land that could be used for normal food production. There is an urgent need to move to second generation biofuels, which utilize non-food plants (and organisms) cultivated on non-agricultural land. 


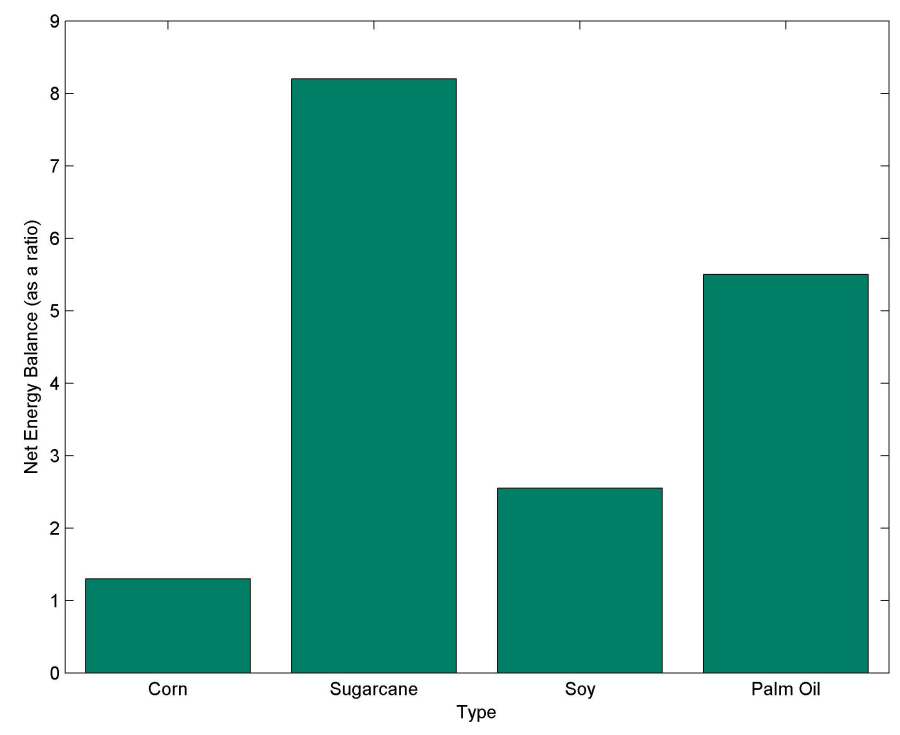

Figure 2: Net energy balance values of first generation biofuels

\section{Second generation biofuels \\ Ethanol from ligno-cellulose}

Perennial plants such as switchgrass are not food crops and can be an excellent source of cellulose, together with wood chippings and industrial/residential waste.

The net energy balance from switchgrass was never less than 14.5 million Joules per litre of bioethanol produced (Tilman et al., 2009). In fact, data from 10 farms in varying conditions across the mid-continental USA also demonstrated an energy yield of 6000 Gigajoules per kilometer squared per year, revealing that ethanol biofuels generated from switchgrass are a very efficient and economically feasible endeavor (Schmer et al., 2008). The bioethanol output per petroleum input ratio for the whole process of production, refining and distribution also averaged at an elevated ratio of 13.1 (Schmer et al., 2008), although compared to bioethanol from corn, the energy yield of bioethanol from switchgrass is - on average almost identical. However, there is still ongoing research on improving the genetics of the cultivated plants (Shen et al., 2013) and industrial microbes (Cha et al., 2013) and in increasing the efficiency of the process of converting biomass to bioethanol.

Environmentally, bioethanol from switchgrass generates $94 \%$ less greenhouse gases (GHG) than an energy-equivalent amount of gasoline. Comparatively, this is much better than corn, which typically generates 25\% less GHG. Hence, switchgrass has greater environmental benefits than corn, has the room to expand on nonagricultural land in the Great Plains of the US, while depending mainly on rain as opposed to irrigation water (Schmer et al., 2008).

In the US, there is no point in expanding further the production of corn as a feedstock for bioethanol production, when a much more environmentally friendly feedstock has an equal energy balance to corn and can be scaled-up to provide significant volume.

\section{Diesel from micro-algae}

The main attraction of microalgae is a current high level of photosynthetic 
efficiency of $5-10 \%$ in practice (Eriksen, 2008) coupled to a high percentage of oil in its dry weight (up to $80 \%$, but realistically $\sim 30 \%$ ). Taken together, these two factors result in a high theoretical yield for biodiesel of 9.84 million litres per kilometer squared per year (Chisti, 2008a), which is an order of magnitude higher than that of palm oil based biodiesel, and oil palm is the highest yielding crops of all cultivated terrestrial plants. In addition, microalgae do not require any arable land for growth, as microalgae are grown in open or closed tanks and tubes deemed photobioreactors (Eriksen, 2008). The water used also does not have to be sweet, as growth can be had in salty or even marine seawater when properly preprocessed (Rodolfi et al., 2009). The high photosynthetic efficiency of microalgae also means that microalgae are a good carbon sink, one that can be used all-year-round (Schenk et al., 2008), as they would be growing in environmentally controlled water tanks in sunny environments.

Despite the obvious potential for biodiesel production from microalgae oil, the worldwide total production of algal biomass in 2010 is 5000 tons (in dry weight), and most of this is used for omega 3 fatty acids and carotenoids, both used as human and animal food supplements (Wijffels and Barbosa, 2010). Why is that?

First, algae if not continually mixed into water will grow flat on the surface of any pool blocking light entry into the pool. Hence, energy-consuming continual mixing is required, but that could come from waste microalgae biomass. In addition, that mixing must ensure penetration of exactly the right amount of sunlight (not too much or too little) to achieve peak photosynthetic conversion performance. Many other factors come into play as well, such as the design of photobioreactors, physiological engineering of the microalgae and continual monitoring of factors such as light intensity and biomass (Eriksen, 2008).
Further, microalgae do not store energy in oil unless they are induced by starvation from nutrients, choking off natural growth processes. This requires the maintenance of the right level of nutrients in the medium, especially nitrogen and phosphorus (Rodolfi et al., 2009). These nutrients come from fertilizers. Having so many nutrients in an open-top water-filled pool is very attractive to invasive species, which will compete with the algae for survival and growth. Hence, it may be necessary to add the equivalent of herbicides to the water body (some still under development) and occasionally drain the whole facility and start over with new microalgae cultures when dealing with exterior open photobioreactors. Both herbicides and fertilizers are typically made from fossil oil. One study claims (Reijnders, 2008) that taking fossil fuel inputs into account gives us a negative energy balance for microalgae of $56 \%$, where more energy is used than produced. This claim was responded to in Chisti, (2008b), where it was asserted that most of the fertilizers come out in the liquid affluent of the anaerobic digesters, which if used in agriculture would result in a positive net energy ratio of 3.3 for microalgal biodiesel. One study shows a yearly yield of 2 million kilograms per kilometer squared for a low-cost photobioreactor in a Mediterranean environment (Rodolfi et al., 2009). Besides nutrients, the production of large amounts of biomass requires large amounts of $\mathrm{CO} 2$, which is not available at the right concentration in normal ambient air. However, CO2 can be cheaply pumped over from a fossil-fuel burning electricity generator, to the microalgae cultivation plant, if both facilities are contiguously located. Finally, the harvesting, oil extraction and even storage and distribution of the harvested oils raise more challenges to the immediate scaling-up of biodiesel production, a necessary step for economic feasibility. Microalgae need to be separated from the water after (induced or spontaneous) flocculation followed by sedimentation or floatation, concluding with 
centrifuging or forced filtration. Using current growth technologies, about $1000 \mathrm{~kg}$ of water need to be processed to harvest just $1 \mathrm{~kg}$ of microalgae biomass (Pienkos and Darzins, 2009). After harvesting, the thick wall of microalgae must be ruptured, physically or/and chemically to allow for the oil to be separated from the rest, possibly using detergents, which must then be separated from the oil (Pienkos and Darzins, 2009).

If it is not yet, it should be clear that there is a wide distance between the real theoretical potential of microalgae as a source of oil for biodiesel production and the very real scientific and engineering challenges that must be met prior to full exploitation of the considerable potential of microalgae.

\section{The environment is not for free}

To produce biomass for biofuel production, one requires land and water, nutrients and herb/pesticides, as well as energy and material (for initial construction and ongoing manufacturing). Energy and material use can be minimized in several ways: using existing infrastructure and machines, constructing efficient buildings and purchasing efficient machines, making full use of the excess biomass and energy generated by the biofuel production process and augmenting that when necessary - with other renewable sources of energy. Fossil oil-based nutrients and herbicides and pesticides should mostly be replaced by natural local organisms (plants, animals and microbes), which may reduce productivity a bit, but will also naturally fight off or divert pests and provide the growing plants with their share of nitrogen, phosphorus and other nutrients (Tilman et al., 2009).

Exclusive use of land for agricultural production of a significant percentage (i.e., multiples of 10\%) of the liquid fuels needed globally, even with the most efficient biotechnologies, will require an area of land comparable to that used for row-crop food production. This will have a huge impact on Earth and human society. One thing we should not do is clear virgin land carelessly, with either excellent carbon sinks (e.g., forests) or high eco-diversity, to use it for energy crop production or to replace food crop production that got displaced by energy crop expansion. This would more than negate - in terms of $\mathrm{CO} 2$ release only - any greenhouse gas reduction benefits flowing from biofuel replacement of fossil fuels. It is much wiser to make use of crop, wood and forest residues (mostly ligno-cellulose), as well as alternating-double-cropping and simultaneous mixed-cropping systems, where both food and energy crops are grown (Chisti, 2008a). Another good idea would be the utilization of degraded land, which had already been used for agriculture, for the sustainable production of perennial plants (e.g., grasses) and fast-growing trees, which do not require much irrigation and that need light amounts of 'green' fertilizers \& herbicides (Tilman et al., 2009).

Water is another precious resource, which must be carefully managed. In the US, it takes 500-4000 litres of water to grow enough crops for 1 litre of bioethanol, in addition to 2-10 litres of water for the refinery. Already, 6 billion $\mathrm{m} 3$ of irrigation water (3\% of total water use in the US) was used in the year 2000 for growing energy crops. According to the US Climate Change Science program, extreme hydrologic events have become more frequent and intense in the past 50 years, and this is part of an ongoing trend (Dominguez-Faus et al., 2009). From a water perspective, an energy crop is one that requires little irrigation, can grow on (mildly treated) wastewater, is drought resistant and yields high volumes of cellulosic biomass per litre of water.

In the US, corn is the main feedstock for bioethanol production while also being the one with the highest nutrient application rate and the highest nutrient loading to surface water, on a per equal land area basis (Dominguez-Faus et al., 2009). The 
bioethanol feedstock, with the lowest nitrogen $(\sim 25 \mathrm{~g} /$ litre) and pesticide (almost 0 ) requirements (Dominguez-Faus et al., 2009), is the one with the highest yield and is the backbone of the Brazilian bioethanol industry: sugarcane. However, in the US, the high fertilizer application rates for crops in the Midwest result in the highest fluxes of nitrogen and phosphorus into the Mississippi River and lead to the expanding hypoxic zone in the Gulf of Mexico (Dominguez-Faus et al., 2009). Soybean, the main feedstock of biodiesel production in the US, requires almost as little fertilizer as sugarcane but much more pesticides (6 g/litre). Even the use of switchgrass (a cellulose source), say in the Chesapeake Bay region, does not negate the need for fertilizers, at a rate of about $3200 \mathrm{~kg}$ of nitrogen $/ \mathrm{km} 2$ of cultivated land (Dominguez-Faus et al., 2009). Nevertheless, the use of cellulosic sources, such as switchgrass, does in general lower the need for agricultural land, irrigation water and agrichemicals.

\section{The alternative alternatives}

Energy sources on Earth can be divided into sub-terrestrial, terrestrial and supraterrestrial (space-bound) in location. Subterrestrial sources include geothermal, fossil and nuclear fission materials; only one of those is renewable: geothermal. Geothermal power contributed $3.9 \%$ of the European Union's (EU) renewable energy (Eurostat, 2012), and is slowly expanding in Canada as a source of home heating. Terrestrial renewable energy sources include: hydropower, other water-movement based power (e.g., tidal), wind power as well as that portion of the sun's radiation that penetrates the atmosphere. In space, given the low density of solar radiation, if humans are to ultimately spread to and transform other planets then they have no option but to perfect the use of nuclear fusion as a cheap and virtually limitless source of energy.

Back on Earth, only a fraction of hydropower sources is still not utilized or about to be so, micro-hydro and tidal power generation is still under development, while wind power is more mature. Wind energy is intermittent, which necessitates energy storage, and is dispersed, which requires grid-based transmission. Nevertheless, in the EU - the most intensive user of renewables - wind turbines contributed $7.7 \%$ of the total renewable energy in 2012, coming in at 3rd place after biomass \& waste (at 67.7\%) and hydropower (at 19\%) (Eurostat, 2012). The breakdown of renewable energy use in the European Union is visualized in Figure 3 with biomass and waste dominating use. It is worth noting that renewable energy provides about $1 / 5$ th of the total EU energy needs, and that nuclear fission energy is the greatest single provider of energy there (Eurostat, 2012). Nuclear fission is not renewable and has serious psychological, weapon proliferation and waste management problems (including decommissioning). 


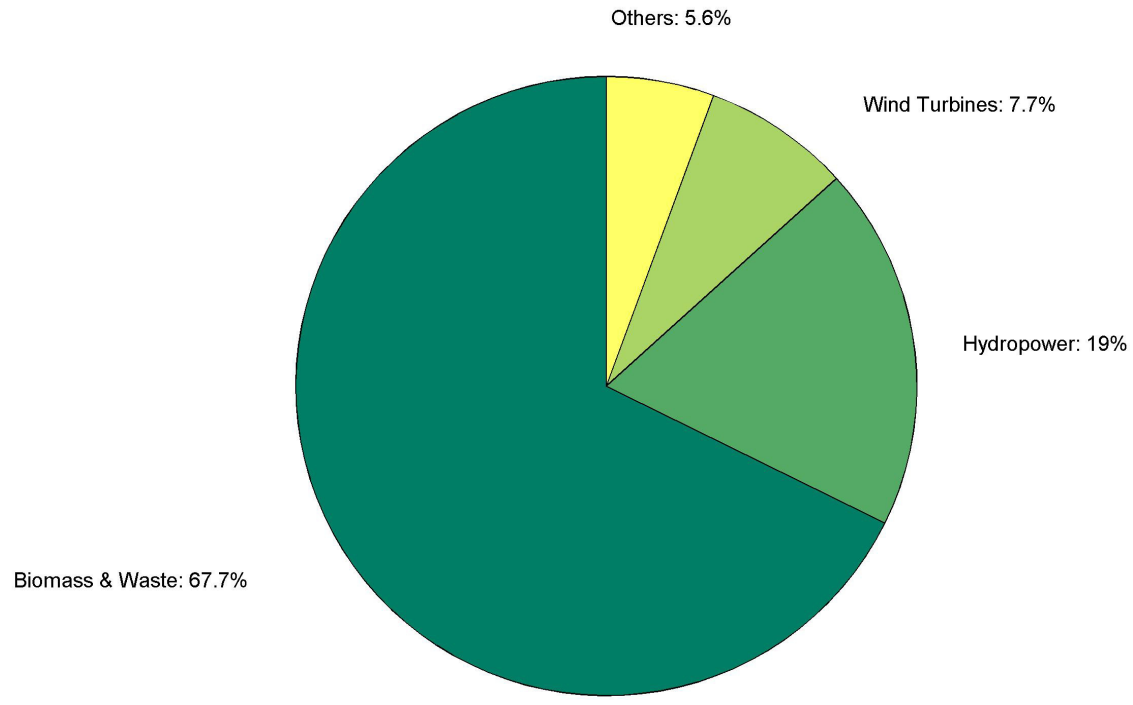

Figure 3: Breakdown of renewable energy use throughout European Union

Solar power generation comes in three forms: solar water heaters, photosyntheticpowered biofuel generation and photovoltaic (PV) \& concentrated solar power (CSP) electricity generation. A full $50 \%$ of the power usage in a modern home is spent on water heating (Armaroli and Balzani, 2007), and most of that could and should be done via solar water heaters. Natural photosynthesis (at 1-2\% conversion efficiency) is the basis of all biofuel production. PV panels, however, have a minimum conversion efficiency of at least 11$15 \%$ and last for an average of 30 years without maintenance; the thermodynamic limit for conversion efficiency is in fact 31\% (Maggio and Cacciola, 2012). Though PVs cannot generate sufficient electricity to directly power electric transportation engines (Walker, 2009), they can be used to charge the batteries of electric and plug-in hybrid vehicles.

Still, there is a significant barrier to the wide utilization of PV generation, and it is cost.
However, this cost is expected to go below the 8 cents/kWh appropriate for residential markets in 2015-2020 (Arvizu, 2008). Those years are expected to mark the beginning of the wide adoption of PV in homes in the developed world. The cost of PV panels will drop further if simpler cheaper lowefficiency technologies such as TiO2 films are dye-sensitized to increase their conversion efficiency to acceptable levels $(11 \%$ and greater). Faster-charging higher-density batteries would also facilitate the transition, and both of these challenges are the subject of intense research, both industrially and academically.

\section{Conclusion}

The need for biofuels stems from the need for liquid fuels for internal combustion engines that run on gasoline, diesel and jet-fuel. There is no doubt that the current source of liquid hydrocarbons - fossil fuels - is drying out. The reserves are vast and, taking coal into account, may or may not last us a 100 
years. The issue is that of supply and demand and of global warming. Once the demand for fossil fuels exceeds supply, as it will do soon, the price of fuel will rise quickly, which given the wide use of fuel in everything from food to plastics - will raise the cost of living for everyone. Global warming, on the other hand, has already started placing costly or irresistible pressures on human and ecological wellbeing. Part of the solution to this dual energy-climate crisis is a move from fossil fuels to renewable non-polluting alternatives. Due to supply limitations, biofuels can only play a part, though significant and potentially lasting, in plugging holes in the sagging supply of liquid fuels. However, biofuels can only form part of a

\section{References}

1. Armaroli, N. and Balzani, V. (2007) "The future of energy supply: Challenges and opportunities," Angewandte Chemie International Edition, 46 (1-2) 52-66.

2. Arvizu, D. (2008) "Potential role and contribution of solar energy to the mitigation of climate change," Proceedings of the IPCC scoping meeting on renewable energy sources, 20-25.

3. Balat, M., Balat, H. and Öz, C. (2008) "Progress in bioethanol processing," Progress in Energy and Combustion Science, 34 (5) 551-573.

4. Bentley, R. W. (2002) "Global oil \& gas depletion: an overview," Energy Policy, 30 (3) 189-205.

5. Bloomberg "Energy \& Oil Prices: Natural Gas, Gasoline and Crude Oil," URL: http://www.bloomberg.com/energy

[Accessed on: March 22, 2013].

6. Bothast, R. J. and Schlicher, M. A. (2005) "Biotechnical processes for conversion of corn into ethanol," Applied Microbial Biotechnology, 67 19-25. strategy that must include significant reduction in global energy demands and increased utilization of both centralized and distributed means of energy generation. While the use of ligno-cellulose is ideal for a biofuel, the land requirements constrain the already limited available area of arable land along with other concerns like greenhouse gas emissions during production. First generation biofuels are easier to yield; however, undesirable energy yields hinder their feasibility. Additional issues such as growth logistics and storage pose concerns. Because of this, diligent considerations must be taken when evaluating energy strategies for near-future use.

7. Carlson, L., Grove, S. J. and Kangun, N. (1993) "A content analysis of environmental advertising claims: A matrix method approach," The Journal of Advertising, 22 (3) 27-39.

8. Cha, M., Chung, D., Elkins, J. G., Guss, A. M. and Westpheling, J. (2013) "Metabolic engineering of Caldicellulosiruptor bescii yields increased hydrogen production from lignocellulosic biomass," Biotechnology for Biofuels, 6 (85).

9. Chisti, Y. (2008a) "Biodiesel from microalgae beats bioethanol," Trends in Biotechnology, 26 (3) 126-131.

10.Chisti, Y. (2008b) "Response to Reijnders: Do biofuels from microalgae beat biofuels from terrestrial plants? ," Trends in Biotechnology, 26 (7) 351-352.

11.Central Intelligence Agency "The world factbook," URL: https://www.cia.gov/library/publications/t he-world-factbook/geos/us.html [Accessed on: June 11, 2014].

12.Dominguez-Faus, R., Powers, S. E., Burken, J. G. and Alvarez, P. J. (2009) "The water footprint of biofuels: A drink or drive issue? ," Environ. Sci. Technol., 43 (9) 3005-3010. 
13.Dunn, J. B., Mueller, S., Kwon, H. and Wang, M. Q. (2013) "Land-use change and greenhouse gas emissions from corn and cellulosic ethanol," Biotechnology for Biofuels, 6 (51).

14.Environmental Protection Agency - Office of Transportation and Air Quality (2008) "Average annual emissions and fuel consumption for gasoline-fueled passenger cars and light trucks", United States: Agency, E. P.

15.Environmental Protection Agency Climate Change Division "Nitrous oxide emissions,"

URL:

http://epa.gov/climatechange/ghgemissions

/gases/n2o.html [Accessed on: December 2, 2013].

16.Eriksen, N. T. (2008) "The technology of microalgal culturing," Biotechnol Lett, 30 (9) 1525-1536.

17.Escobar, J. C., Lora, E. S., Venturini, O. J., Yáñez, E. E., Castillo, E. F. and Almazan, O. (2009) "Biofuels: Environment, technology and food security," Renewable and Sustainable Energy Reviews, 13 (6-7) 12751287.

18.European Commission (2012) "Europe in figures - Eurostat yearbook 2012", Eurostat

19.FAO (2008) Biofuels: prospects, risks and opportunities, Food and Agriculture Organization of the United Nations, Rome

20.Fargione, J. E., Plevin, R. J. and Hill, J. (2010) "The ecological impact of biofuels," Annual Review of Ecology, Evolution, and Systematics, 41 351-377.

21.Farrell, A. E., Plevin, R. J., Turner, B. T., Jones, A. D., O'Hare, M. and Kammen, D. M. (2006) "Ethanol can contribute to energy and environmental goals," Science, 311 (5760) 506-508.

22.Gasparatos, A., Stromberg, P. and Takeuchi, K. (2013) "Sustainability impacts of first-generation biofuels," Animal Frontiers, 3 (2) 12-26.

23.Giulietti, A. M., Harley, R. M., De Queiroz, L. P., Wanderley, M. D. G. L. and Van Den Berg, C. (2005) "Biodiversidad y conservación de plantas en Brasil," Conservation Biology, 19 (3) 632-639.

24.Goldemberg, J. (2008) "The Brazilian biofuels industry," Biotechnology for Biofuels, 1 (6).

25.Goldemberg, J. (2007) "Ethanol for a sustainable energy future," Science, 315 (5813) 808-810.

26.Goldemberg, J., Coelho, S. T. and Guardabassi, P. (2008) "The sustainability of ethanol production from sugarcane," Energy Policy, 36 (6) 2086-2097.

27.Goldemberg, J. and Guardabassi, P. (2009) "Are biofuels a feasible option?," Energy Policy, 37 (1) 10-14.

28.Greene, D. L., Hopson, J. and Li, J. (2006) "Have we run out of oil yet? Oil peaking analysis from an optimist's perspective," Energy Policy, 34 (5) 515-531.

29.He, B. Q., Shuai, S. J., Wang, J. X. and He, H. (2003) "The effect of ethanol blended diesel fuels on emissions from a diesel engine," Atmospheric Environment, 37 (35) 49654971.

30.Hertwich, E. G., Pease, W. S. and Koshland, C. P. (1997) "Evaluating the environmental impact of products and production processes: A comparison of six methods," Science of the Total Environment, 1 (9) 1329.

31.Hill, J., Nelson, E., Tilman, D., Polasky, S. and Tiffany, D. (2006) "Environmental, economic, and energetic costs and benefits of biodiesel and ethanol biofuels," Proceedings of the National Academy of Sciences of the 
United States of America, 103 (30) 1120611210.

32.International Energy Agency (2008) "World energy outlook 2008", Paris: IEA

33.Independent Petroleum Association of America "Global petroleum demand: Longterm focus," URL: http://oilindependents.org/globalpetroleum-demand-long-term-focus/ [Accessed on: May 15, 2014].

34.Kim, S. and Dale, B. E. (2005) "Life cycle assessment of various cropping systems utilized for producing biofuels: Bioethanol and biodiesel," Biomass and Bioenergy, 29 (6) 426-439.

35.Knight, R. F. and Pretty, D. J. (1996) The impact of catastrophes on shareholder value, Templeton College,

36.Luciani, G. (2003) "Emerging challenges in the field of energy policy for Europe, the USA and Russia," Proceedings of Oil, Gas \& Energy Law Intelligence, 1 (5).

37.Maggio, G. and Cacciola, G. (2012) "When will oil, natural gas, and coal peak?," Fuel, 98 (111-123).

38. Mitchell, D. (2008) "A note on rising food prices," Policy Research Working Paper, 4682.

39.Nogueira, L. A. H. (2011) "Does biodiesel make sense?," Energy Policy, 36 (6) 36593666.

40.Olson, R. D. (2006) Below-cost feed crops: An indirect subsidy for industrial animal factories, Institute for Agriculture and Trade Policy, United States

41.Ortiz, L., Schlesinger, S. and Noronha, S. (2006) Agribusiness and biofuels: An explosive mixture - Impacts of monoculture expansion on bioenergy production in Brazil, FBOMS, Brazil 42.0wen, N. A., Inderwildi, O. R. and King, D. A. (2010) "The status of conventional world oil reserves - Hype or cause for concern?," Energy Policy, 38 (8) 4743-4749.

43.Pienkos, P. T. and Darzins, A. (2009) "The promise and challenges of microalgalderived biofuels," Biofuels, Bioproducts and Biorefining, 3 (4) 431-440.

44.Pleanjai, S. and Gheewala, S. H. (2009) "Full chain energy analysis of biodiesel production from palm oil in Thailand," Applied Energy, 86 (Supplement 1) 209-214.

45.Pradhan, A., Shrestha, D. S., Van Gerpen, J. and Duffield, J. (2008) "The energy balance of soybean oil biodiesel production: A review of past studies," Transactions of the ASAE (American Society of Agricultural Engineers), 51 (1) 185-197.

46. Ravishankara, A. R., Daniel, J. S. and Portmann, R. W. (2009) "Nitrous oxide (N20): The dominant ozone-depleting substance emitted in the 21st century," Science, 326 (5949) 123-125.

47.Reijnders, L. (2008) "Do biofuels from microalgae beat biofuels from terrestrial plants?," Trends in Biotechnology, 26 (7) 349-350.

48. Research and Innovate Technology Administration "Number of U.S. aircraft, vehicles, vessels, and other conveyances," URL:

http://www.rita.dot.gov/bts/sites/rita.dot.g ov.bts/files/publications/national_transport ation_statistics/html/table_01_11.html [Accessed on: May 13, 2014].

49.Robbins, P. T. (2001) Greening the corporation: Management strategy and the environmental challenge, Earthscan, United States

50. Robertson, G. P., Paul, E. A. and Harwood, R. R. (2000) "Greenhouse gases in intensive agriculture: Contributions of individual gases

Nawwaf Kharma, Lance Lafontaine and Richard Fenster (2016), International Journal of Renewable Energy and Biofuels, DOI: 10.5171/2016.650634 
to the radiative forcing of the atmosphere," Science, 289 (5486) 1922-1925.

51.Rodolfi, L., Chini Zittelli, G., Bassi, N., Padovani, G., Biondi, N., Bonini, G. and Tredici, M. R. (2009) "Microalgae for oil: Strain selection, induction of lipid synthesis and outdoor mass cultivation in a low-cost photobioreactor," Biotechnology and Bioengineering, 102 (1) 100-112.

52. Rooney, L. W. and Pflugfelder, R. L. (1986) "Factors affecting starch digestibility with special emphasis on sorghum and corn," J. Anim Sci., 63 (5) 1607-1623.

53.Rothenberg, S., Briscoe, F., Marcus, A. and Maxwell, J. (2002) "Green schemes: Corporate environmental strategies and their implementation."

54.Scharlemann, J. P. W. and Laurance, W. F. (2008) "How green are biofuels?," Science, 319 (5859) 43-44.

55.Schenk, P. M., Thomas-Hall, S. R., Stephens, E., Marx, U. C., Mussgnug, J. H., Posten, C., Kruse, O. and Hankamer, B. (2008) "Second generation biofuels: High-efficiency microalgae for biodiesel production," BioEnergy Research, 1 (1) 20-43.

56.Schmer, M. R., Vogel, K. P., Mitchell, R. B. and Perrin, R. K. (2008) "Net energy of cellulostic ethanol from switchgrass," Proceedings of the National Academy of Sciences of the United States of America, 105 464-469.

57.Shafiee, S. and Topal, E. (2009) "When will fossil fuel reserves be diminished?," Energy Policy, 37 (1) 181-189.

58.Shen, H., Poovaiah, C. R., Ziebell, A., Tschaplinksi, T. J., Pattahil, S., Gjersing, E., Engle, N. L., Katahira, R., Pu, Y., Sykes, R., Chen, F., Ragauskas, A. J., Mielenz, J. R., Hahn, M. G., Davis, M., Srewart, C. N. J. and Dixon, R. A. (2013) "Enhanced characteristics of genetically modified switchgrass (Panicum virgatum L.) for high biofuel production," Biotechnology for Biofuels, 6 (71).
59.Sorrell, S., Miller, R., Bentley, R. and Speirs, J. (2010a) "Oil futures: A comparison of global supply forecasts," Energy Policy, 38 (9) 4990-5003.

60.Sorrell, S., Speirs, J., Bentley, R., Brandt, A. and Miller, R. (2010b) "Global oil depletion: A review of the evidence," Energy Policy, 38 (9) 5290-5295.

61.Srivastava, A. and Prasad, R. (2000) "Triglycerides-based diesel fuels," Renewable and Sustainable Energy Reviews, 4 (2) 111133.

62.Tilman, D., Socolow, R., Foley, J. A., Hill, J., Larson, E., Lynd, L., Pacala, S., Reilly, J., Searchinger, T., Somerville, C. and Williams, R. (2009) "Beneficial biofuels - The food, energy, and environment trilemma," Science, 325 (5938) 270-271.

63.U.S. Geological Survey (2000) "USGS world petroleum assessment 2000: Description and results by USGS World Energy Assessment Team", United States: Interior, U. S. D. o.

64.Walker, D. A. (2009) "Biofuels, facts, fantasy, and feasibility," Journal of Applied Phycology, 21 (5) 509-517.

65.Wijffels, R. H. and Barbosa, M. J. (2010) "An outlook on microalgal biofuels," Science, 329 (5993) 796-799.

66.Yeboah, A., Naanwaab, C., Yeboah, O., Owens, J. and Bynum, J. (2012) "Economic feasibility of sustainable high oilseed-based biofuel production: The case for biodiesel in North Carolina," International Food and Agribusiness Management Review 16 (1) 4166.

67.Yusoff, S. (2006) "Renewable energy from palm oil - Innovation on effective utilization of waste," Journal of Cleaner Production, 14 (1) 87-93. 